\title{
Simultaneous removal of turbidity and humic acid from high turbidity stormwater
}

\author{
Gurusamy Annadurai, S.S. Sung, Duu-Jong Lee* \\ Department of Chemical Engineering, National Taiwan University, Taipei 106, Taiwan, ROC
}

Accepted 4 April 2003

\begin{abstract}
This work studied the simultaneous removal of turbidity and humic acid from high turbidity synthetic raw water using polyaluminum chloride ( $\mathrm{PACl}$ ) as the coagulant. The response surface method with the Box-Behnken design of experiments was adopted to investigate the effects of $\mathrm{pH}$, turbidity and alkalinity of suspension, the doses of $\mathrm{PACl}$ and the dosed amount of humic acid. The non-dimensional correlations for the residual turbidity and humic acid in the supernatant were obtained by regression analysis. Graphical presentation facilitates data interpretation from designed experiments. The most significant variables to the coagulation and sedimentation process were identified. Simultaneous removal of both turbidity and humic acid from the high turbidity water is reachable at neutral $\mathrm{pH}$, and the PACl dose is selected if the raw water turbidity has not become too high. Extremely high turbidity stormwater may be treated using single-stage PACl coagulation to satisfactorily remove both the turbidity and humic acid from the water. The proposed strategy was applied to successfully treat the extremely high turbidity stormwater, brought by storm Nari on September 16-19, 2001.
\end{abstract}

(c) 2003 Elsevier Science Ltd. All rights reserved.

Keywords: High turbidity; Polyaluminum chloride (PACl); Humic acid; Drinking water

\section{Introduction}

In drinking water industries, coagulants, such as polyaluminum chloride $(\mathrm{PACl})$, are used in the raw water to coagulate small particles into settleable flocs. The turbidity of raw water is the target substance to be removed during coagulation-sedimentation treatment. Many factors influence the coagulation performance, including $\mathrm{pH}$ and alkalinity of the suspension, turbidity of the raw water, coagulant dose, organic contents and others (Kawamura, 1991; Masschelein, 1992). Humic substances are the main organic compounds affecting the coagulation processes, and their removal has attracted extensive research interest owing to the potential

\footnotetext{
*Corresponding author. Fax: + 886-2-2362-3040.

E-mail address: djlee@ccms.ntu.edu.tw (D.-J. Lee).
}

formation of tri-chloromethane (THM) in the disinfection stage (Rebhun and Lurie, 1993).

Narkis and Rebhun (1990) revealed that when both mineral particles and dissolved humic substance exist in the solution, the latter controls the coagulation process. The optimal $\mathrm{pH}$ value for humic acid removal ranges from 5 to 6 , while that for clay suspensions is 6.5-7.5 (Hall and Packham, 1965; Edwards and Amirtharajah, 1985). Precipitation and adsorption are the two major mechanisms for the removal of organics, using hydrolyzing salts (O'Melia, 1991; Dempsey et al., 1984; Dempsey, 1989). Edzwald proposed a parallel-series reaction pathway for the interactions between alum and the humic substances (Edzwald, 1993). Other authors refined the pathways in their model systems (Dentel, 1988; Hundt and O'Melia, 1988). The presence of humic substances yields bulky flocs, whose settleability is poor hence leading to high supernatant turbidity 
(Tambo and Watanabe, 1979; Rebhun et al., 1984; Rebhun, 1990).

Conventional coagulation and sedimentation processes work very well for raw water of low to medium turbidity. Tropical storms frequently hit Pacific-Rim regions, like Taiwan, and yield heavy rain and produce stormwater of high turbidity. For instance, on 23rd August 2000, the tropical storm Bilis hit Taiwan and caused serious flooding. The raw water for PingTsan Waterworks of Taiwan Water Supply Corporation increased its turbidity up to 1200 NTU for over a week and to several hundred NTU for over a month. The total organic carbon (TOC) of the raw water also increased to more than $10 \mathrm{ppm}$. Simultaneous removal of turbidity and organic substances from high turbidity water is of practical significance. Pre-sedimentation followed by conventional coagulation and flocculation with a filter aid is commonly proposed for treating high turbidity water (Li and Gregory, 1991; Cotton et al., 1994; Heinzmann, 1994; Zhu et al., 1996; Janssens and Buekens, 1993). Selvapathy and Reddy (1992) and Yu and Somasundaran (1993) demonstrated the superiority of using dual conditioners, hydrolyzing metal salts and polyelectrolyte, rather than a single conditioner to treat high-turbidity water. However, the risk to human health of applying polyelectrolytes and their degradation products in drinking water is still not conclusive. The maintenance and operation of Waterworks would become much easier if the use of a conventional singlestage coagulation process for low turbidity raw water could be successfully applied to high turbidity raw water cases. The removal efficiency of organic substances is also a key issue for tuning process variables.

In this work, we investigated the coagulation and sedimentation treatment of high-turbidity raw water. A large number of experiments are needed to comprehensively investigate the effects of numerous variables on the efficiency of coagulation-sedimentation processes. Herein, we adopted the response surface method using the Box-Behnken design of experiments (Box and Behnken, 1960), to give the correlations for the turbidity and the humic acid level in the coagulated supernatant.

\section{Experimental}

\subsection{Materials and test}

Humic acid with a carbon content of $52.6 \%$ was purchased from the International Humic Substances Society (IHSS). Other chemicals were from Merck (Taiwan). Raw water samples were prepared by mixing prescribed amounts of UK ball clay powders and stock solution of humic acid with $10^{-2} \mathrm{~N} \mathrm{NaClO}_{4}$ solution. The alkalinity was adjusted by adding $\mathrm{NaHCO}_{3}$ salt.
The $\mathrm{pH}$ was adjusted by using $\mathrm{HClO}_{4}$ and $\mathrm{NaOH}$. The clay powder has a monodispersed distribution with a mean diameter of approximately $4.1 \mu \mathrm{m}$. The solid density was determined using a Micromeritics Accupyc 1330 pycnometer as $2,580 \mathrm{~kg} / \mathrm{m}^{3}$. The stock solution of humic acid was prepared by first dissolving the chemicals at $\mathrm{pH}$ 12. After filtering with a $0.45 \mu \mathrm{m}$ membrane, the $\mathrm{pH}$ of the filtrate was adjusted back to 7 for further use.

The humic-kaolin suspension was placed into a stirred tank, which was a cylindrical tank whose diameter and height were both $15 \mathrm{~cm}$. The $\mathrm{PACl}$ solution (containing $10 \% \mathrm{w} / \mathrm{w}_{2} \mathrm{Al}_{2} \mathrm{O}_{3}$ ) was gradually injected into the stirred tank at $90 \mathrm{rpm}$ for $1.5 \mathrm{~min}$ and subsequently $50 \mathrm{rpm}$ for $8.5 \mathrm{~min}$. The coagulated samples were settled freely for $2 \mathrm{~h}$. Thereafter, the supernatant sample was carefully withdrawn for measurement. The turbidity of the supernatant was measured using a turbidimeter (HACH model $2100 \mathrm{AN}$ ). Before coagulation, at pH 7 and 500 ppm clay dose, the turbidities for synthetic raw water was approximately 200 NTU at various humic acid concentrations, presenting high turbidity waters. Moreover, without the addition of clay or $\mathrm{PACl}$, the turbidity of the suspension was generally lower than 0.6 NTU regardless of the concentrations of humic acid or the suspension alkalinity. We hence neglect the role of humic acid in suspension turbidity in the further discussions. The humic acid level in the supernatant, after filtration with a $0.45 \mu \mathrm{m}$ membrane, was monitored using a $\mathrm{UV}_{254}$ absorption test with an UV-Vis Spectrometer (Spectronic Genesys 5). A linear correlation exists between the $\mathrm{UV}_{254}$ reading and the humic acid content. The humic acid concentration could be derived from the $\mathrm{UV}_{254}$ reading. Before coagulation, the $\mathrm{UV}_{254}$ data for synthetic raw water at $\mathrm{pH} 7$ and humic acid dose of $14 \mathrm{ppm}$ and raw water turbidity of 0,100 and 200 NTU were approximately 0.21 , indicating dissolved humic acid concentrations of $4.7 \mathrm{ppm}$.

Each experiment was duplicated under identical conditions. In most of the cases the reproducibility was within $2 \%$.

\subsection{Experimental design}

The response surface method using the Box-Behnken design of experiments, gives the correlations for the turbidity and the humic acid concentration of the coagulated supernatant. The response surface method is an empirical modeling method used to evaluate the relationship between a set of controllable experimental factors and observed results. Factors considered in this work include the $\mathrm{pH}$ value, the humic acid concentration (ppm), the raw water turbidity (NTU), the PACl dose (ppm) and the alkalinity (ppm as $\mathrm{NaHCO}_{3}$ ) as the 
Table 1

Experimental design

\begin{tabular}{|c|c|c|c|c|c|}
\hline Id no. & $\mathrm{pH}\left(X_{1}\right)$ & Humic acid (ppm) $\left(X_{2}\right)$ & Turbidity (NTU) $\left(X_{3}\right)$ & $\mathrm{PACl}(\mathrm{ppm})\left(X_{4}\right)$ & $\mathrm{NaHCO}_{3}(\mathrm{ppm})\left(X_{5}\right)$ \\
\hline 1 & $5(-1)$ & $0(-1)$ & $100(0)$ & $100(0)$ & $100(0)$ \\
\hline 2 & $9(1)$ & $0(-1)$ & $100(0)$ & $100(0)$ & $100(0)$ \\
\hline 3 & $5(-1)$ & $28(1)$ & $100(0)$ & $100(0)$ & $100(0)$ \\
\hline 4 & $9(1)$ & $28(1)$ & $100(0)$ & $100(0)$ & $100(0)$ \\
\hline 5 & $7(0)$ & $14(0)$ & $0(-1)$ & $80(-1)$ & $100(0)$ \\
\hline 6 & $7(0)$ & $14(0)$ & $200(1)$ & $80(-1)$ & $100(0)$ \\
\hline 7 & $7(0)$ & $14(0)$ & $0(-1)$ & $120(1)$ & $100(0)$ \\
\hline 8 & $7(0)$ & $14(0)$ & $200(1)$ & $120(1)$ & $100(0)$ \\
\hline 9 & $7(0)$ & $0(-1)$ & $100(0)$ & $100(0)$ & $0(-1)$ \\
\hline 10 & $7(0)$ & $28(1)$ & $100(0)$ & $100(0)$ & $0(-1)$ \\
\hline 11 & $7(0)$ & $0(-1)$ & $100(0)$ & $100(0)$ & $200(1)$ \\
\hline 12 & $7(0)$ & $28(1)$ & $100(0)$ & $100(0)$ & $200(1)$ \\
\hline 13 & $5(-1)$ & $14(0)$ & $0(-1)$ & $100(0)$ & $100(0)$ \\
\hline 14 & $9(1)$ & $14(0)$ & $0(-1)$ & $100(0)$ & $100(0)$ \\
\hline 15 & $5(-1)$ & $14(0)$ & $200(1)$ & $100(0)$ & $100(0)$ \\
\hline 16 & $9(1)$ & $14(0)$ & $200(1)$ & $100(0)$ & $100(0)$ \\
\hline 17 & $7(0)$ & $14(0)$ & $100(0)$ & $80(-1)$ & $0(-1)$ \\
\hline 18 & $7(0)$ & $14(0)$ & $100(0)$ & $120(1)$ & $0(-1)$ \\
\hline 19 & $7(0)$ & $14(0)$ & $100(0)$ & $80(-1)$ & $200(1)$ \\
\hline 20 & $7(0)$ & $14(0)$ & $100(0)$ & $120(1)$ & $200(1)$ \\
\hline 21 & $7(0)$ & $0(-1)$ & $0(-1)$ & $100(0)$ & $100(0)$ \\
\hline 22 & $7(0)$ & $28(1)$ & $0(-1)$ & $100(0)$ & $100(0)$ \\
\hline 23 & $7(0)$ & $0(-1)$ & $200(1)$ & $100(0)$ & $100(0)$ \\
\hline 24 & $7(0)$ & $28(1)$ & 200(1) & $100(0)$ & $100(0)$ \\
\hline 25 & $5(-1)$ & $14(0)$ & $100(0)$ & $80(-1)$ & $100(0)$ \\
\hline 26 & $9(1)$ & $14(0)$ & $100(0)$ & $80(-1)$ & $100(0)$ \\
\hline 27 & $5(-1)$ & $14(0)$ & $100(0)$ & 120(1) & $100(0)$ \\
\hline 28 & $9(1)$ & $14(0)$ & $100(0)$ & $120(1)$ & $100(0)$ \\
\hline 29 & $7(0)$ & $14(0)$ & $0(-1)$ & $100(0)$ & $0(-1)$ \\
\hline 30 & $7(0)$ & $14(0)$ & $200(1)$ & $100(0)$ & $0(-1)$ \\
\hline 31 & $7(0)$ & $14(0)$ & $0(-1)$ & $100(0)$ & $200(1)$ \\
\hline 32 & $7(0)$ & $14(0)$ & $200(1)$ & $100(0)$ & $200(1)$ \\
\hline 33 & $5(-1)$ & $14(0)$ & $100(0)$ & $100(0)$ & $0(-1)$ \\
\hline 34 & $9(1)$ & $14(0)$ & $100(0)$ & $100(0)$ & $0(-1)$ \\
\hline 35 & $5(-1)$ & $14(0)$ & $100(0)$ & $100(0)$ & $200(1)$ \\
\hline 36 & $9(1)$ & $14(0)$ & $100(0)$ & $100(0)$ & $200(1)$ \\
\hline 37 & $7(0)$ & $0(-1)$ & $100(0)$ & $80(-1)$ & $100(0)$ \\
\hline 38 & $7(0)$ & $28(1)$ & $100(0)$ & $80(-1)$ & $100(0)$ \\
\hline 39 & $7(0)$ & $0(-1)$ & $100(0)$ & $100(0)$ & $100(0)$ \\
\hline 40 & $7(0)$ & $28(1)$ & $100(0)$ & $100(0)$ & $100(0)$ \\
\hline 41 & $7(0)$ & $14(0)$ & $100(0)$ & $100(0)$ & $100(0)$ \\
\hline 42 & $7(0)$ & $14(0)$ & $100(0)$ & $100(0)$ & $100(0)$ \\
\hline 43 & $7(0)$ & $14(0)$ & $100(0)$ & $100(0)$ & $100(0)$ \\
\hline 44 & $7(0)$ & $14(0)$ & $100(0)$ & $100(0)$ & $100(0)$ \\
\hline 45 & $7(0)$ & $14(0)$ & $100(0)$ & $100(0)$ & $100(0)$ \\
\hline 46 & $7(0)$ & $14(0)$ & $100(0)$ & $100(0)$ & $100(0)$ \\
\hline
\end{tabular}

critical variables; they are designated as $X_{1}$ to $X_{5}$, respectively. All other factors except the $\mathrm{PACl}$ dose is considered to be related to the compositions of the raw water.

The low, middle and high levels of each variable were designated as $-1,0$ and +1 , respectively, and are listed in Table 1. The parametric range, which was investigated, covers the high turbidity raw water com- monly noted in Taiwan's rivers after the tropical storms. The independent variables $X_{i}$ and the mathematical relationship of the response $Y$ to these variables can be approximated by a quadratic polynomial equation:

$$
Y=b_{0}+\sum_{i=1}^{5} b_{i} X_{i}+\sum_{i=1}^{5} \sum_{j=1}^{i} b_{j i} X_{i} X_{j}
$$


Table 2

Experimental and theoretically predicted values

\begin{tabular}{|c|c|c|c|c|}
\hline \multirow[t]{2}{*}{ Id no. } & \multicolumn{2}{|c|}{ Turbidity $\left(Y_{1}, \mathrm{NTU}\right)$} & \multicolumn{2}{|c|}{$\mathrm{UV}_{254}\left(Y_{2},-\right)$} \\
\hline & Experiment & Predicted & Experiment & Predicted \\
\hline 1 & 7.5 & 7.3 & 0.20 & 0.20 \\
\hline 2 & 11.4 & 11.1 & 0.06 & 0.06 \\
\hline 3 & 10.9 & 10.8 & 0.03 & 0.03 \\
\hline 4 & 8.9 & 8.7 & 0.36 & 0.36 \\
\hline 5 & 0.1 & 0.1 & 0.19 & 0.19 \\
\hline 6 & 9.1 & 9.1 & 0.11 & 0.11 \\
\hline 7 & 11.0 & 10.9 & 0.05 & 0.05 \\
\hline 8 & 1.4 & 1.4 & 0.21 & 0.21 \\
\hline 9 & 1.4 & 1.1 & 0.09 & 0.09 \\
\hline 10 & 3.3 & 3.1 & 0.14 & 0.14 \\
\hline 11 & 2.0 & 2.0 & 0.10 & 0.10 \\
\hline 12 & 1.0 & 1.1 & 0.18 & 0.18 \\
\hline 13 & 2.1 & 2.1 & 0.06 & 0.06 \\
\hline 14 & 18.5 & 18.5 & 0.22 & 0.22 \\
\hline 15 & 17.3 & 17.4 & 0.16 & 0.16 \\
\hline 16 & 2.7 & 2.8 & 0.19 & 0.19 \\
\hline 17 & 4.1 & 3.9 & 0.08 & 0.08 \\
\hline 18 & 8.9 & 8.7 & 0.19 & 0.19 \\
\hline 19 & 6.5 & 6.6 & 0.24 & 0.24 \\
\hline 20 & 4.8 & 4.8 & 0.09 & 0.09 \\
\hline 21 & 1.0 & 0.9 & 0.06 & 0.06 \\
\hline 22 & 1.8 & 1.8 & 0.14 & 0.14 \\
\hline 23 & 1.0 & 1.1 & 0.11 & 0.11 \\
\hline 24 & 1.2 & 1.3 & 0.16 & 0.16 \\
\hline 25 & 0.8 & 0.6 & 0.13 & 0.13 \\
\hline 26 & 25.3 & 25.2 & 0.25 & 0.25 \\
\hline 27 & 26.0 & 25.8 & 0.14 & 0.14 \\
\hline 28 & 3.2 & 3.0 & 0.21 & 0.21 \\
\hline 29 & 2.5 & 2.6 & 0.09 & 0.09 \\
\hline 30 & 3.1 & 3.0 & 0.13 & 0.13 \\
\hline 31 & 2.7 & 2.6 & 0.12 & 0.12 \\
\hline 32 & 2.0 & 1.8 & 0.16 & 0.16 \\
\hline 33 & 11.8 & 12.3 & 0.10 & 0.10 \\
\hline 34 & 9.3 & 9.7 & 0.21 & 0.21 \\
\hline 35 & 8.1 & 8.3 & 0.14 & 0.14 \\
\hline 36 & 12.4 & 12.5 & 0.23 & 0.23 \\
\hline 37 & 3.9 & 4.2 & 0.12 & 0.12 \\
\hline 38 & 3.8 & 3.9 & 0.19 & 0.19 \\
\hline 39 & 4.4 & 4.8 & 0.11 & 0.11 \\
\hline 40 & 6.0 & 6.2 & 0.16 & 0.16 \\
\hline 41 & 0.2 & 0.2 & 0.10 & 0.10 \\
\hline 42 & 0.2 & 0.2 & 0.10 & 0.10 \\
\hline 43 & 0.2 & 0.2 & 0.10 & 0.10 \\
\hline 44 & 0.2 & 0.2 & 0.10 & 0.10 \\
\hline 45 & 0.2 & 0.2 & 0.10 & 0.10 \\
\hline 46 & 0.2 & 0.2 & 0.10 & 0.10 \\
\hline
\end{tabular}

where $Y=$ predicted response, $b_{0}=$ constant, $b_{i}=$ linear coefficients $(i=1-5), b_{i i}=$ quadratic coefficients, and $b_{j i}=$ cross product coefficients $(i \neq j) . Y$ denotes either the residual turbidity or the $\mathrm{UV}_{254}$ absorption data in supernatant. For either of the cases, a total of 41 experiments were needed to estimate the coefficient of the model using multiple linear regression analysis. The above equation was solved using the design expert (Stat-Ease Inc., Statistics made-Easy, Minneapolis, MN version 5.0.7.1999) to estimate the response of the independent variables.

\section{Results and discussion}

\subsection{Experimental results}

Table 2 lists the measured turbidity and $\mathrm{UV}_{254}$ data under the experimental conditions listed in Table 1. The minimum residual turbidity of supernatant measured with 100 NTU raw water is 0.1 NTU under the condition of $\mathrm{pH} 7,14 \mathrm{ppm}$ dosed humic acid, $100 \mathrm{ppm} \mathrm{PACl}$ dose and $100 \mathrm{ppm} \mathrm{NaHCO}_{3}$. The minimum $\mathrm{UV}_{254}$ absorption datum achievable with $14 \mathrm{ppm}$ dosed humic acid is 0.05 , equivalent to $1.13 \mathrm{ppm}$ humic acid $(92 \%$ reduction), which occurs at $\mathrm{pH} 7,120 \mathrm{ppm} \mathrm{PACl}, 100$ ppm $\mathrm{NaHCO}_{3}$ and with no clay addition.

Fig. 1 shows the turbidity vs. humic acid data for the supernatant. No clear correlation between these two variables is noticeable. We tried to fix certain process variables, like $\mathrm{pH}$ or $\mathrm{PACl}$ dose, for re-plotting Fig. 1. We could not get satisfactory correlation between the turbidity and humic acid data with further constraints.

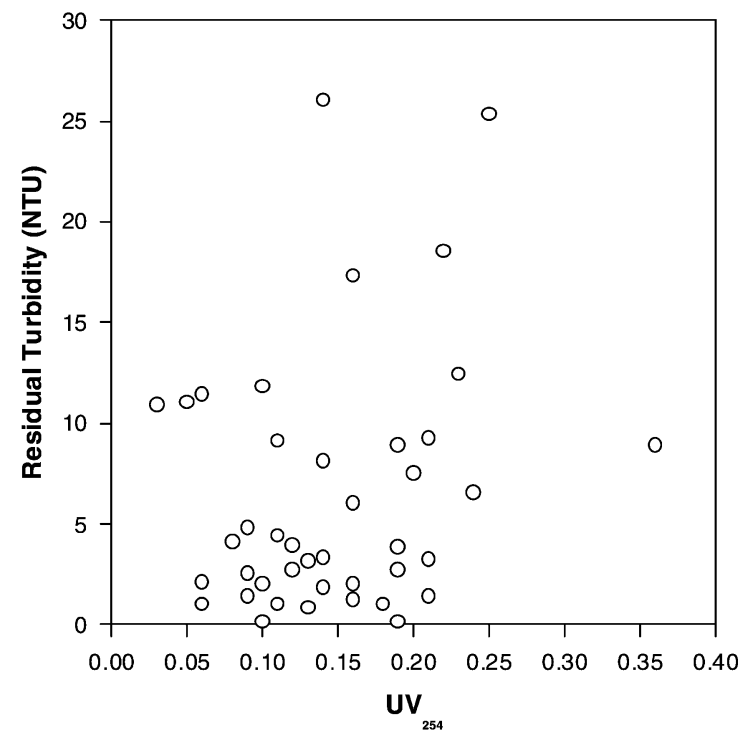

Fig. 1. The residual turbidity vs. residual humic acid data plot. 
The removal mechanisms of both substances are hence different.

\subsection{Regression model}

To obtain the optimal values of independent variables, the regression equation was obtained following the design method. Table 3 lists the fitted coefficients of the regression model, Eq. (1) on the basis of the experimental data, including 5 linear, 5 quadratic and 10 interaction terms and 1 block term. To directly compare the significance of various variables in Eq. (1), the best-fitted second-order polynomials are nondimensionlized using the reference variables as follows: $X_{10}=7, X_{20}=14 \mathrm{ppm}, X_{30}=100 \mathrm{NTU}, X_{40}=100 \mathrm{ppm}$ and $X_{50}=100 \mathrm{ppm}$. The non-dimensional equation for residual turbidity in supernatant is as follows:

$$
\begin{aligned}
& \left(\frac{Y_{1}}{0.15 \mathrm{NTU}}\right)=1+20.0\left(\frac{X_{1}}{X_{10}}\right)+18.0\left(\frac{X_{2}}{X_{20}}\right) \\
& +0.16\left(\frac{X_{3}}{X_{30}}\right)+506\left(\frac{X_{4}}{X_{40}}\right) \\
& -0.19\left(\frac{X_{5}}{X_{50}}\right)+2980\left(\frac{X_{1}}{X_{10}}\right)^{2} \\
& +153\left(\frac{X_{2}}{X_{20}}\right)^{2}+0.375\left(\frac{X_{3}}{X_{30}}\right)^{2} \\
& +293000\left(\frac{X_{4}}{X_{40}}\right)^{2}+0.095\left(\frac{X_{5}}{X_{50}}\right)^{2} \\
& -690\left(\frac{X_{1}}{X_{10}}\right)\left(\frac{X_{2}}{X_{20}}\right)-90.4\left(\frac{X_{1}}{X_{10}}\right) \\
& \times\left(\frac{X_{3}}{X_{30}}\right)-55200\left(\frac{X_{1}}{X_{10}}\right)\left(\frac{X_{4}}{X_{40}}\right) \\
& +7.90\left(\frac{X_{1}}{X_{10}}\right)\left(\frac{X_{5}}{X_{50}}\right)-2.80\left(\frac{X_{2}}{X_{20}}\right) \\
& \times\left(\frac{X_{3}}{X_{30}}\right)+2730\left(\frac{X_{2}}{X_{20}}\right)\left(\frac{X_{4}}{X_{40}}\right) \\
& -4.80\left(\frac{X_{2}}{X_{20}}\right)\left(\frac{X_{3}}{X_{30}}\right)-775\left(\frac{X_{3}}{X_{30}}\right) \\
& \times\left(\frac{X_{4}}{X_{40}}\right)-0.0500\left(\frac{X_{3}}{X_{30}}\right) \\
& \times\left(\frac{X_{5}}{X_{50}}\right)-110\left(\frac{X_{4}}{X_{40}}\right)\left(\frac{X_{5}}{X_{50}}\right) \text {. }
\end{aligned}
$$

While the correlation for humic acid data for supernatant is as follows:

$$
\begin{aligned}
& \left(\frac{Y_{2}}{2.26 \mathrm{ppm}}\right)=1+3.36\left(\frac{X_{1}}{X_{10}}\right)+3.20\left(\frac{X_{2}}{X_{20}}\right) \\
& +0.0450\left(\frac{X_{3}}{X_{30}}\right)-9.60\left(\frac{X_{4}}{X_{40}}\right) \\
& -0.0140\left(\frac{X_{5}}{X_{50}}\right)+25.0\left(\frac{X_{1}}{X_{10}}\right)^{2} \\
& +11.0\left(\frac{X_{2}}{X_{20}}\right)^{2}+0.0468\left(\frac{X_{3}}{X_{30}}\right)^{2} \\
& +330\left(\frac{X_{4}}{X_{40}}\right)^{2}+0.00180\left(\frac{X_{5}}{X_{50}}\right)^{2} \\
& +8.40\left(\frac{X_{1}}{X_{10}}\right)\left(\frac{X_{2}}{X_{20}}\right)-56.0\left(\frac{X_{1}}{X_{10}}\right) \\
& \times\left(\frac{X_{3}}{X_{30}}\right)-91.0\left(\frac{X_{1}}{X_{10}}\right)\left(\frac{X_{4}}{X_{40}}\right) \\
& -0.0350\left(\frac{X_{1}}{X_{10}}\right)\left(\frac{X_{5}}{X_{50}}\right) \\
& +0.188\left(\frac{X_{2}}{X_{20}}\right)\left(\frac{X_{3}}{X_{30}}\right) \\
& -50.0\left(\frac{X_{2}}{X_{20}}\right)\left(\frac{X_{4}}{X_{40}}\right) \\
& +0.170\left(\frac{X_{2}}{X_{20}}\right)\left(\frac{X_{5}}{X_{50}}\right) \\
& +14.8\left(\frac{X_{3}}{X_{30}}\right)\left(\frac{X_{4}}{X_{40}}\right) \\
& -0.000250\left(\frac{X_{3}}{X_{30}}\right) \\
& \times\left(\frac{X_{5}}{X_{50}}\right)-6.40\left(\frac{X_{4}}{X_{40}}\right)\left(\frac{X_{5}}{X_{50}}\right) \text {. }
\end{aligned}
$$

Table 2a and $\mathrm{b}$ compares the experimental data with the predicted values from the fitted model equations and the agreement is satisfactory.

\subsection{Significant variables}

Table 4 lists the analysis of variance (ANOVA) for the response function $\left(Y_{i}\right)$ in the coded level of variables. The results indicate a curvilinear interactive relationship between the response function and the variables, as reflected by the large mean sum of squares and $F$-values of total quadratic and interactive effects. The model fits the residual turbidity of supernatant at $R^{2}=0.999$ and $F$ value of 1680 at a significance level of 0.0001. Meanwhile, at the same significance level, the humic acid data could be fit at $R^{2}=0.999$ and $F$ value $=1950$

Using Eq. (2a) and Eq. (2b) the 'sensitivity' of the investigated variables to the turbidity and humic acid 
Table 3

Regression analysis for the residual turbidity and the organic levels in supernatant and quadratic response surface model fitting (ANOVA)

\begin{tabular}{|c|c|c|c|c|c|c|c|c|c|c|}
\hline \multirow[t]{2}{*}{ Source } & \multicolumn{5}{|l|}{ Turbidity } & \multicolumn{5}{|l|}{$\mathrm{UV}_{254}$} \\
\hline & Sum of squares & Degrees of freedom & Mean square & $F$ value & $P$ value & Sum of squares & Degrees of freedom & Mean square & $F$ value & $P$ value \\
\hline Model & 1800 & 20 & 89.8 & 1680 & $<0.0001$ & 0.18 & 20 & $9.09 \times 10^{3}$ & 1947 & $<0.0001$ \\
\hline Residual & 1.34 & 25 & 0.053 & & & $1.1 \times 10^{4}$ & 25 & $4.6 \times 10^{6}$ & & $<0.0001$ \\
\hline Lack of fit & 1.34 & 20 & 0.067 & $6.3 \times 10^{7}$ & $<0.0001$ & $1.1 \times 10^{4}$ & 20 & $5.8 \times 10^{6}$ & $6.3 \times 10^{7}$ & \\
\hline Pure error & 0.00 & 5 & 0.000 & & & 0.000 & 5 & 0.000 & & \\
\hline Correlation total & 1440 & 45 & & & & 0.18 & 45 & & & \\
\hline$R^{2}$ & $R^{2}$ & 0.999 & $\operatorname{Adj} R^{2}$ & 0.998 & & $R^{2}$ & 0.9994 & $\operatorname{Adj} R^{2}$ & 0.9988 & \\
\hline
\end{tabular}


Table 4

Coefficients of the model

\begin{tabular}{|c|c|c|c|c|c|c|c|c|}
\hline \multirow[t]{2}{*}{ Coefficient } & \multicolumn{4}{|c|}{ Turbidity (NTU) } & \multicolumn{4}{|c|}{$\mathrm{UV}_{254}(-)$} \\
\hline & Value & Standard error & $t$ for $\mathrm{H}_{0}:$ coeff. $=0$ & Prob. $>/ t /$ value & Value & Standard error & $t$ for $\mathrm{H}_{0}:$ coeff. $=0$ & Prob. $>/ t /$ value \\
\hline$b_{0}$ & 0.15 & 0.094 & & & 0.10 & $8.82 \times 10^{4}$ & & \\
\hline$b_{1}$ & 0.44 & 0.058 & 7.63 & $<0.0001^{*}$ & 0.048 & $5.4 \times 10^{4}$ & 89.06 & $<0.0001^{*}$ \\
\hline$b_{2}$ & 0.27 & 0.058 & 4.74 & $<0.0001^{*}$ & 0.032 & $5.4 \times 10^{4}$ & 58.99 & $<0.0001^{*}$ \\
\hline$b_{3}$ & -0.10 & 0.058 & -1.81 & 0.0829 & 0.018 & $5.4 \times 10^{4}$ & 33.54 & $<0.0001^{*}$ \\
\hline$b_{4}$ & 0.76 & 0.058 & 13.1 & $<0.0001^{*}$ & -0.0090 & $5.4 \times 10^{4}$ & -16.77 & $<0.0001^{*}$ \\
\hline$b_{5}$ & -0.29 & 0.058 & -5.09 & $<0.0001^{*}$ & 0.014 & $5.4 \times 10^{4}$ & 26.49 & $<0.0001^{*}$ \\
\hline$b_{11}$ & 9.12 & 0.078 & 117 & $<0.0001^{*}$ & 0.051 & $7.3 \times 10^{4}$ & 69.48 & $<0.0001^{*}$ \\
\hline$b_{22}$ & 0.23 & 0.078 & 2.92 & $0.0072^{*}$ & 0.011 & $7.3 \times 10^{4}$ & 14.58 & $<0.0001^{*}$ \\
\hline$b_{33}$ & 0.90 & 0.078 & 11.5 & $<0.0001^{*}$ & 0.0075 & $7.3 \times 10^{4}$ & 10.25 & $<0.0001^{*}$ \\
\hline$b_{44}$ & 4.39 & 0.078 & 56.1 & $<0.0001^{*}$ & 0.033 & $7.3 \times 10^{4}$ & 45.22 & $<0.0001^{*}$ \\
\hline$b_{55}$ & 1.43 & 0.078 & 18.3 & $<0.0001^{*}$ & 0.018 & $7.3 \times 10^{4}$ & 24.49 & $<0.0001^{*}$ \\
\hline$b_{12}$ & -1.48 & 0.12 & -12.8 & $<0.0001^{*}$ & 0.12 & $1.08 \times 10^{3}$ & 108.96 & $<0.0001^{*}$ \\
\hline$b_{13}$ & -7.75 & 0.12 & -67.1 & $<0.0001^{*}$ & -0.032 & $1.08 \times 10^{3}$ & -29.84 & $<0.0001^{*}$ \\
\hline$b_{14}$ & -11.8 & 0.12 & -102 & $<0.0001^{*}$ & -0.013 & $1.08 \times 10^{3}$ & -11.57 & $<0.0001^{*}$ \\
\hline$b_{15}$ & 1.70 & 0.12 & 14.7 & $<0.0001^{*}$ & -0.005 & $1.08 \times 10^{3}$ & -4.63 & $<0.0001^{*}$ \\
\hline$b_{23}$ & -0.17 & 0.12 & -1.47 & 0.1538 & -0.007 & $1.08 \times 10^{3}$ & -6.71 & $<0.0001^{*}$ \\
\hline$b_{24}$ & 0.41 & 0.12 & 3.55 & $0.0016^{*}$ & -0.005 & $1.08 \times 10^{3}$ & -4.63 & $<0.0001^{*}$ \\
\hline$b_{25}$ & -0.73 & 0.12 & -6.32 & $<0.0001^{*}$ & 0.007 & $1.08 \times 10^{3}$ & 6.48 & $<0.0001^{*}$ \\
\hline$b_{34}$ & -4.65 & 0.12 & -402 & $<0.0001^{*}$ & 0.059 & $1.08 \times 10^{3}$ & 54.59 & $<0.0001^{*}$ \\
\hline$b_{35}$ & -0.32 & 0.12 & -2.77 & $0.0104^{*}$ & 0.001 & $1.08 \times 10^{3}$ & 0.93 & 0.3636 \\
\hline$b_{45}$ & -1.65 & 0.12 & -14.3 & $<0.0001^{*}$ & -0.064 & $1.08 \times 10^{3}$ & -59.45 & $<0.0001^{*}$ \\
\hline
\end{tabular}

"Significant factor. 


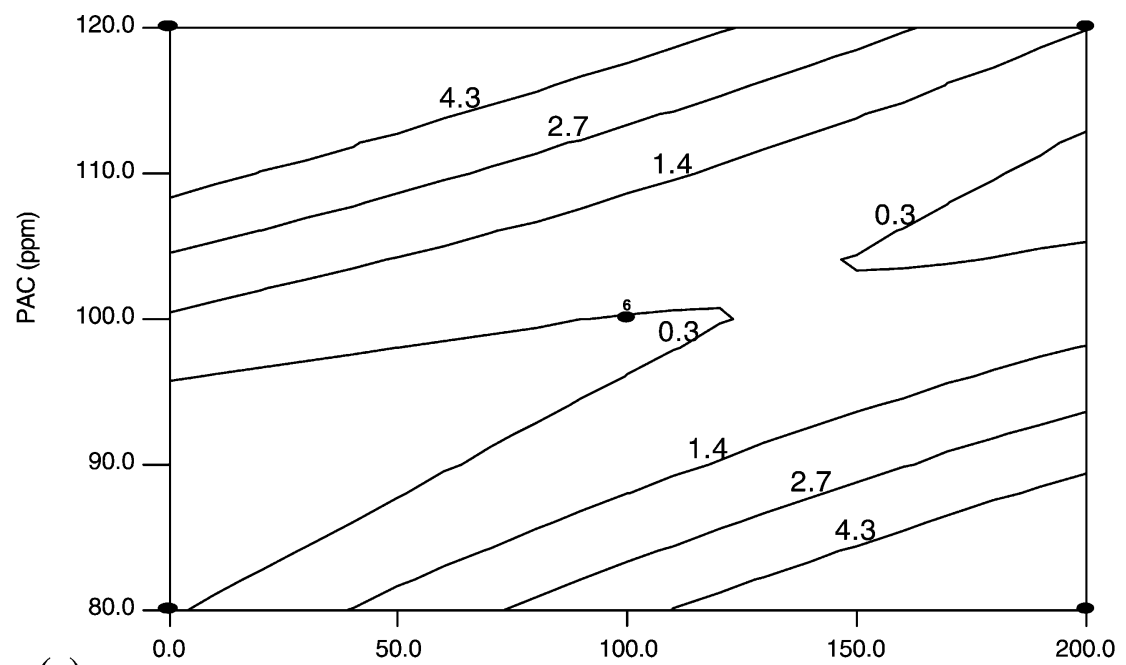

(a)

Raw water turbitity (NTU)

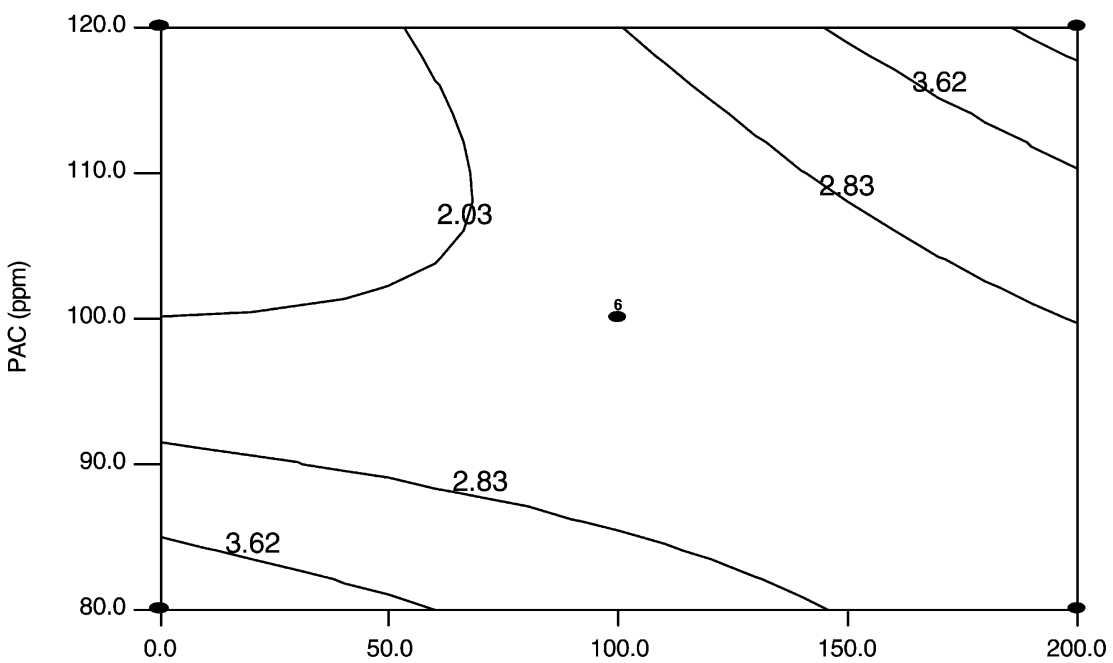

(b)

Raw water turbitity (NTU)

Fig. 2. (a) Contour plot for residual turbidity vs. PACl dose and raw water turbidity. $\mathrm{pH} 7,14 \mathrm{ppm}$ humic acid dose, $100 \mathrm{ppm}$ $\mathrm{NaHCO}_{3}$. (b) Contour plot for residual humic acid data vs. PACl dose and raw water turbidity. pH 7, 14 ppm humic acid dose, 100 ppm $\mathrm{NaHCO}_{3}$.

removal efficiencies could be compared. For turbidity removal, the significance of variables follows: $X_{4}$ (PACl dose) $\gg X_{1} \quad(\mathrm{pH}), X_{2} \quad$ (humic acid) $\gg X_{3} \quad$ (raw water turbidity), $X_{5}$ (alkalinity); while the interactions between $X_{4}$ and $X_{1}$ or $X_{2}$ are the most profound ones. On the other hand, for humics removal, the significance becomes: $X_{1} \fallingdotseq X_{2} \fallingdotseq X_{4} \gg X_{3} \gg X_{5}$; while the most influential interaction pairs remain the $\left(X_{1}-X_{4}\right)$ and $\left(X_{2}-\right.$ $X_{4}$ ) pairs. That is, the PACl dose is the most significant variable to turbidity and humics removal efficiencies.
For the latter, the effects of $\mathrm{pH}$ value and humic acid concentration are also significant. Under the investigated range neither the turbidity nor the alkalinity of raw water plays an essential role for the coagulation-sedimentation processes.

\subsection{Process optimization}

Fig. 2a, Fig. 2b, Fig. 3a, Fig. 3b, Fig. 4a and Fig. 4b present the contour plots for residual turbidity and humic 


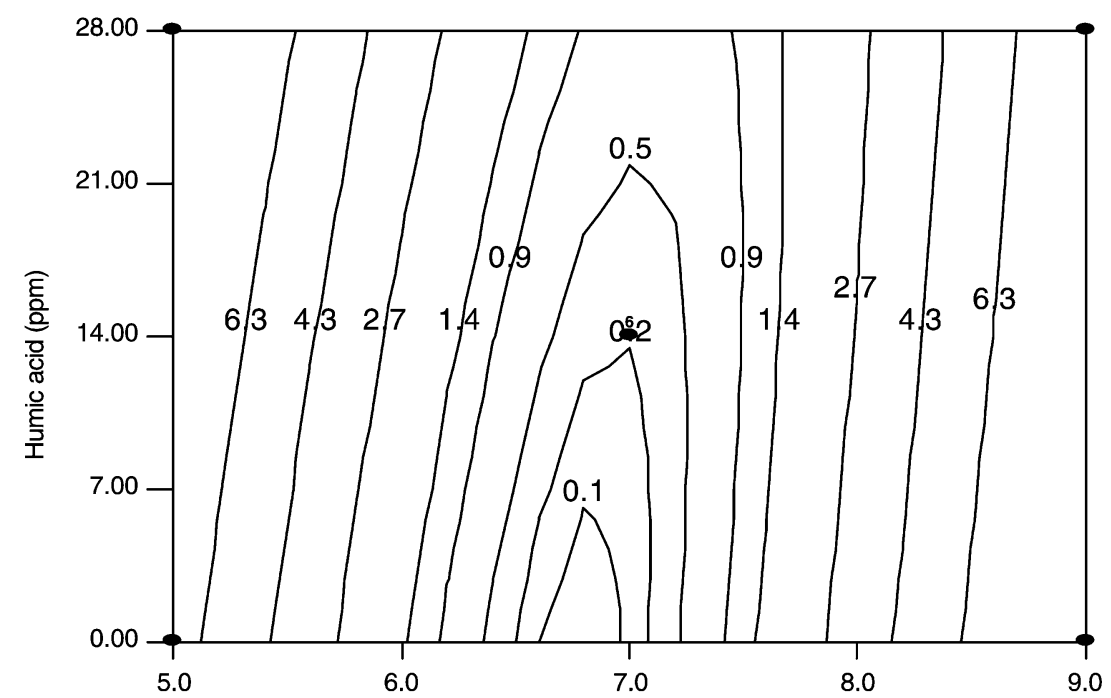

(a)

$\mathrm{pH}$

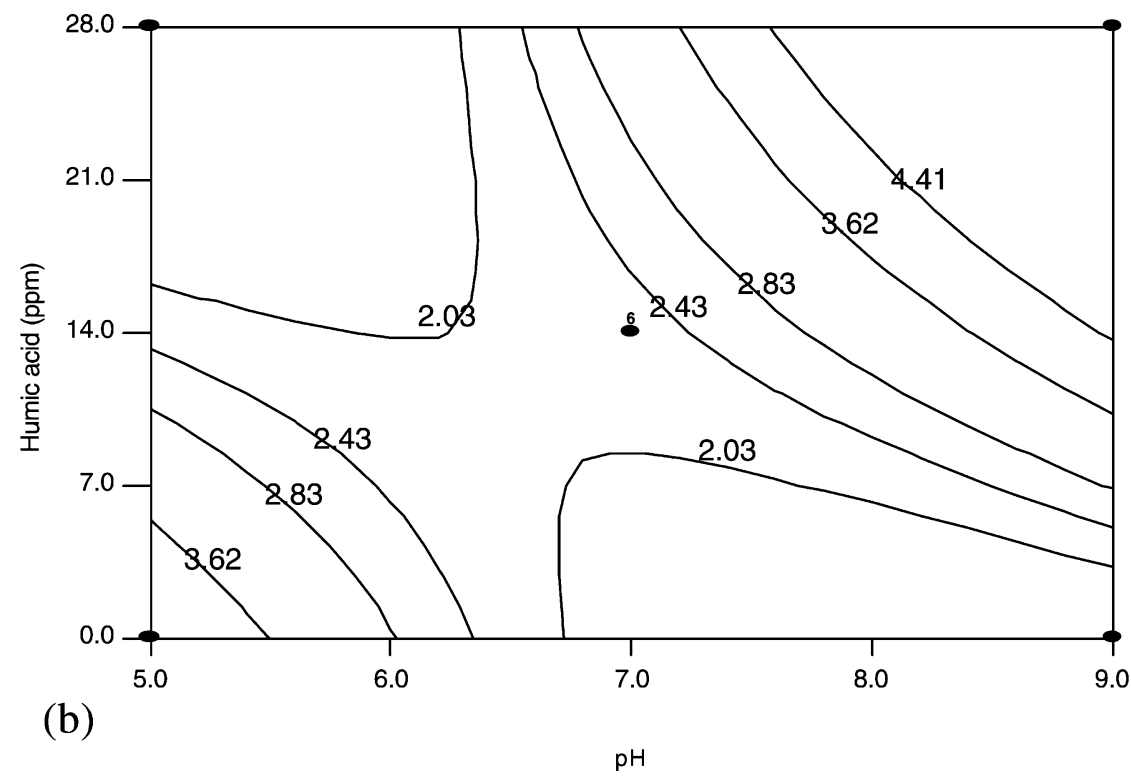

Fig. 3. (a) Contour plot for residual turbidity vs. dosed humic acid and $\mathrm{pH}$ value. $\mathrm{pH} 7,100 \mathrm{NTU}$ raw water, $100 \mathrm{ppm}$ PACl dose. (b) Contour plot for residual humic acid data vs. dosed humic acid and $\mathrm{pH}$ value. $\mathrm{pH}$ 7, $100 \mathrm{NTU}$ raw water, $100 \mathrm{ppm} \mathrm{PACl}$ dose.

acid data as functions of process variables $X_{1}-X_{5}$. Fig. 2a indicates that an optimal 'window' exists along which the $\mathrm{PACl}$ dose required for sufficient turbidity removal increases with raw water turbidity, as commonly noted in practice. Overdosing deteriorates supernatant quality, referring to the 'restabilization' of the suspended particles. For humics removal, as shown in Fig. 2b, at low to medium raw water turbidity, the humic acid data decrease monotonically with increasing $\mathrm{PACl}$ dose. The presence of clay particles has a negative impact on humic acid removal, owing to the carryover of the suspended particles with strongly adsorbed humic substance on the clay particle surface, or the competition between clay particles and humics for the dosed PACl.

Fig. 3a and $\mathrm{b}$ demonstrated that the optimal $\mathrm{pH}$ ranges for turbidity and humics removal from high 
(a)

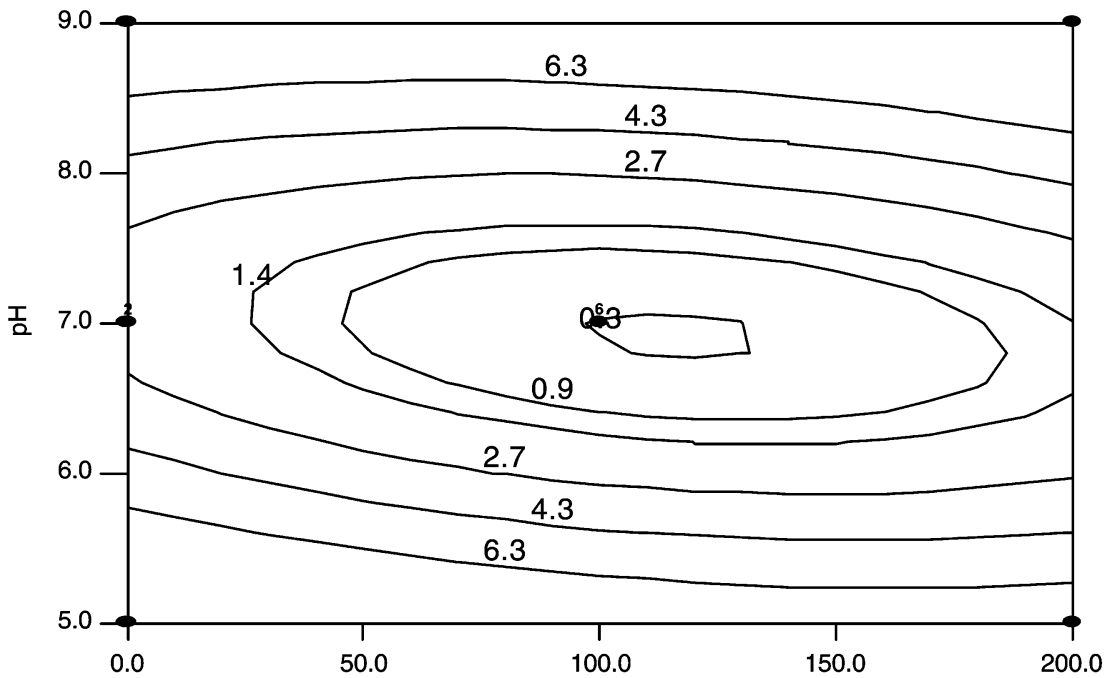

(b)

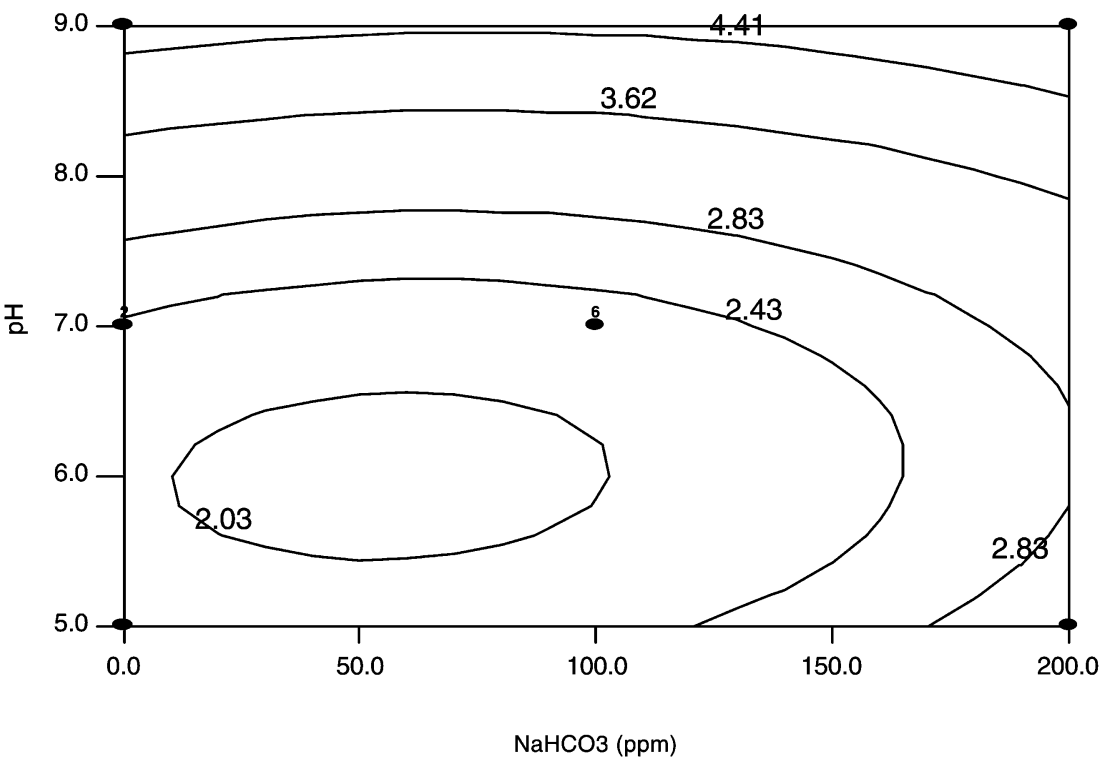

Fig. 4. (a) Contour plot for residual turbidity vs. pH value and $\mathrm{NaHCO}_{3}$ concentration. 14 ppm dosed humic acid, $100 \mathrm{NTU}$ raw water turbidity, $100 \mathrm{ppm} \mathrm{PACl}$ dose. (b) Contour plot for residual humic acid data vs. $\mathrm{pH}$ value and $\mathrm{NaHCO}_{3}$ concentration. 14 ppm dosed humic acid, 100 NTU raw water turbidity, 100 ppm PACl dose.

turbidity waters are $6.5-7.5$ and 5-6, respectively, which correlates with literature results (Hall and Packham, 1965). High humic acid concentration is harmful to turbidity removal at all $\mathrm{pH}$ 's, but facilitates humics removal around $\mathrm{pH} 5$. At low clay dose, the residual humic acid decreases in a linear manner with the PACl dose over a wide experimental range. (Note: The high residual humic acid concentration depicted in Fig. 3b reveals the poor removal efficiency of the released organic matter from clay particles, which is clearly illustrated in Table 2.)

Fig. 4a reveals that the suspension alkalinity is relatively insensitive to the turbidity removal. On the other hand, as shown in Fig. 4b, the humics removal prefers (mildly) high alkalinity.

The Box-Behnken design has been employed in 
Table 5

Experimental results for high turbidity raw water after the hit by tropical storm Nari. Raw water turbidity of 1650 NTU, humic acid of $1.34 \mathrm{ppm}$

\begin{tabular}{|c|c|c|c|c|}
\hline Id no. & $\mathrm{pH}$ & $\mathrm{PACl}$ dose (ppm) & Supernatant turbidity (NTU) & Supernatant humic acid level (ppm) \\
\hline 1 & 7 & 80 & 1.05 & 0.81 \\
\hline 2 & 7 & 180 & 3.52 & 0.81 \\
\hline 3 & 7 & 130 & 0.11 & 0.90 \\
\hline 4 & 7 & 130 & 1.14 & 0.75 \\
\hline 5 & 5 & 130 & 5.18 & 0.93 \\
\hline 6 & 9 & 130 & 2.54 & 1.02 \\
\hline
\end{tabular}

combination with response surface methodology (RSM) to estimate the minimum residual turbidity and the minimum humic acid level. Under the condition of $\mathrm{pH}$ 6.5-7.2, humic acid 0-10 ppm, raw water turbidity 4045 NTU, PACl dose 90-110 ppm and a wide range of alkalinity, it is estimated that the minimum turbidity of supernatant could be reduced to less than 0.1 NTU. The minimum humic acid level for the supernatant at 0.68 ppm occurs under the condition of $\mathrm{pH} 5-6$, humic acid 21-28 ppm, raw water turbidity 0-20 NTU, PACl dose $>110 \mathrm{ppm}$ and alkalinity $>50 \mathrm{ppm}$. (Note: There is a small range at very low humic acid level that exhibits a low $\mathrm{UV}_{254}$ reading. This occurrence is trivial and is neglected in further discussions.) As shown in Fig. 2a, Fig. 2b, Fig. 3a, Fig. 3b, Fig. 4a and Fig. 4b, the variables $X_{1}, X_{2}$ and $X_{4}$ do have a strong influence on the turbidity and humics removal efficiencies. Neither the raw water turbidity nor $\mathrm{NaHCO}_{3}$ significantly affect the coagulation-sedimentation efficiency.

\subsection{Simultaneous removal of turbidity and humic acid}

The 'optimal' conditions for removing turbidity or humic acid from high turbidity water are different. Simultaneous removal of both substances in a single unit needs a compromise. In practice the humic acid concentration and the turbidity in raw water are not controllable. The significance of controlling variables includes $\mathrm{pH}$ value and $\mathrm{PACl}$ dose.

The contours for residual NTU (Fig. 3a) presents an area of minimum value at $\mathrm{pH}$ 6.7-7.2. Departing from neutral conditions the supernatant turbidity markedly increases. A neutral $\mathrm{pH}$ value is hence selected for facilitating turbidity removal. As addressed above, the contour plot for humic acid data (Fig. 3b) presents a saddle-point characteristic. At $\mathrm{pH}$ 6.7-7.2 the residual humic acid supernatant increases with its dose. However, the dependence changes at different humic acid range. At humic acid $<10$ ppm, as commonly noted in drinking water treatment practice, all the residual humic acid data approximately ranges from 1.81 to $2.03 \mathrm{ppm}$, which is close to the background value yielded by the clay particles. Restated, in conjunction with the 'optimal' turbidity removal, this $\mathrm{pH}$ range presents sufficient humic acid removal as well.

The remaining significant variable is $\mathrm{PACl}$ dose. According to Fig. $2 \mathrm{a}$ and $\mathrm{b}$ the optimal dose for $\mathrm{PACl}$ increases linearly with the raw water turbidity. For instance, at raw water turbidity of 100 and 200 NTU, the optimal $\mathrm{PACl}$ dose ranges from 92 to $102 \mathrm{ppm}$ and 103 to 113 ppm, respectively. On the other hand, the 'window' for optimal PACl dose on humic acid removal is relatively wider. For instance, at raw water turbidity of $100 \mathrm{NTU}, 85-120 \mathrm{ppm} \mathrm{PACl}$ is required to reach the residual humic acid of 2.0-2.7 ppm (81-93\% reduction). Too high or too low $\mathrm{PACl}$ dose would yield a marked increase in humic acid in supernatant. The required $\mathrm{PACl}$ decreases with increasing raw water turbidity. This trend is inconsistent with that observed for turbidity removal. Hence, the optimal PACl dose for removing humic acid differs from that for turbidity if the raw water turbidity is either higher than 160 NTU or lower than 30 NTU. Only at a medium level of raw water turbidity could coagulation with $\mathrm{PACl}$ alone simultaneously remove both turbidity and humic acid from water. For an extremely high turbidity stormwater the chosen dose presents a compromise.

\subsection{Field application}

On September 16-19, 2001, tropical storm Nari hit Taiwan and brought heavy rain and serious flooding. The turbidity of Da-Han River, Taoyuan, which is the main surface water source for Taoyuan County, Taiwan increased to 1650 NTU and the humic acid concentration was $1.34 \mathrm{ppm}$. We applied the proposed dosing strategy to treat the high turbidity stormwater in the field. Restated, the most significant variables for treating this high turbidity raw water included the $\mathrm{pH}$ value and the PACl dose; a neutral condition is recommended for the former, and comprise should be made for the latter. The alkalinity of suspension is not significant. Hence, we first adjusted the $\mathrm{pH}$ value of the raw water to neutral. Then the PACl was dosed at three levels (80, 
130 and $180 \mathrm{ppm})$ while the turbidity and humic acid concentration data for supernatant were monitored and listed in Table 5. Apparently, the best turbidity removal was achieved at a medium PACl dose of $130 \mathrm{ppm}$. Over- or under-dosing led to an increase in supernatant turbidity. This dose, however, yielded a humic acid concentration of $0.90 \mathrm{ppm}$ ( $33 \%$ reduction), which was greater than those obtained at the other two doses investigated. To remove humic acid to $0.75 \mathrm{ppm}$ (44\% reduction) at $180 \mathrm{ppm}$ dose of $\mathrm{PACl}$, however, the turbidity increased to $3.52 \mathrm{NTU}$, which was unacceptable in practice. Hence, a PACl dose at $80 \mathrm{ppm}$ was recommended to reach acceptable turbidity (1.05 NTU) and humic acid levels $(0.81 \mathrm{ppm})$ of supernatant.

The tests at $\mathrm{pH} 5$ and 9 were also conducted for comparison sake, which were also summarized in Table 5. Apparently the performance is far from satisfactory and is disregarded in practice. The dosing strategy proposed in this work thereby successfully treated the extremely high turbidity stormwater to acceptable levels using single-stage $\mathrm{PACl}$ dosing control.

\section{Conclusions}

Simultaneous removal of turbidity and humic acid from high turbidity raw water was investigated in this work by adopting the response surface method with the Box-Behnken design of experiments. The significant variables considered are the $\mathrm{pH}$, turbidity and alkalinity of raw water, the $\mathrm{PACl}$ dose and the humic acid concentration. The turbidity and the residual humic acid level in supernatant do not correspond with each other to a significant level. Their non-dimensional correlations were obtained separately by regression analysis. Graphical presentation was facilitated with each result from designed experiments. The most influential process variable to sufficient turbidity removal is the coagulant dose. For humics removal, besides the $\mathrm{PACl}$ dose, both the $\mathrm{pH}$ value and the humics concentration are significant variables.

The optimal conditions for removing turbidity and humic acid from a given high turbidity water are different. Simultaneous removal of both substances from water in a single unit needs a compromise. A neutral $\mathrm{pH}$ value is selected for facilitating turbidity removal. The supernatant turbidity could reach a sufficiently low value. Meanwhile, most humic acid could be effectively removed at neutral $\mathrm{pH}$ using a medium $\mathrm{PACl}$ dose, if the raw water turbidity did not exceed 160 NTU. At extremely high turbidity, one cannot use single-stage $\mathrm{PACl}$ coagulation to simultaneously remove both the turbidity and the humic acid. The proposed strategy for the single-stage $\mathrm{PACl}$ dosing system was successfully applied to coagulate the stormwater brought by storm
Nari of turbidity 1650 NTU and humic acid concentration of $1.34 \mathrm{ppm}$.

\section{References}

Box, G.E.P., Behnken, D.W., 1960. Some new three levels design for the study of quantitative variables. Technometrics 2, 455-475.

Cotton, A.P., Elis, K.V., Khowaja, M.A., 1994. Some options for water treatment in disaster situations. J. Water SRTAqua 43, 303-310.

Dempsey, B.A., 1989. Reactions between fulvic acids and aluminium. In: Suffer, I.N., MacCarthy, P. (Eds.), Aquatic Humic Substances: Influence on Fate and Treatment of Pollutants. American Chemistry Society, Washington, pp. 409-424.

Dempsey, B.A., Ganho, R.M., O’Melia, C.R., 1984. The coagulation of humic substances by means of aluminum salts. J. AWWA 76, 141-150.

Dentel, S.K., 1988. Application of the precipitation charge neutralization model of coagulation. Environ. Sci. Technol. 22, 825-833.

Edwards, G.A., Amirtharajah, A., 1985. Removing color caused by humic acids. J. AWWA 77, 50-57.

Edzwald, J.K., 1993. Coagulation in drinking water treatment: particles, organics and coagulants. Water Sci. Technol. 27 (1), 21-35.

Hall, E.S., Packham, R.F., 1965. Coagulation of organic color with hydrolysing coagulant. J. AWWA 57, 1149-1166.

Heinzmann, B., 1994. Coagulation and flocculation of stormwaer from a separate seer system-a new possibility for enhanced treatment. Water Sci. Technol. 29 (12), 267-278.

Hundt, T.R., O’Melia, C.R., 1988. Aluminum-fulvic acid interactions: mechanisms and applications. J. AWWA 80, $176-186$

Janssens, J.G., Buekens, A., 1993. Assessment of process selection for particle removal in surface water treatment. J. Water SRT-Aqua 42, 279-288.

Kawamura, S., 1991. Integrated Design of Water Treatment Facilities. John Wiley and Sons, NY.

Li, G., Gregory, J., 1991. Flocculation and sedimentation of high-turbidity waters. Water Res. 25, 1137-1143.

Masschelein, W.J., 1992. Unit Processes in Drinking Water Treatment. Marcel Dekker, NY.

Narkis, N., Rebhun, M., 1990. Flocculation of fulvic acidsclay minerals suspensions. Proceedings of the 21st Annual Meeting of the Fine Particle Society, pp. 1-25.

O'Melia, C.R., 1991. Practice, theory, and solid-liquid separation. J. Water SRT-Aqua 40, 371-379.

Rebhun, M., 1990. Floc formation and breakup in continuous flora flocculation and in contact filtration. In: Hahn, H.H., Klute, R. (Eds.), Chemical Water and Wastewater Treatment. Springer-Verlag, Berlin, pp. 117-126.

Rebhun, M., Lurie, M., 1993. Control of organic matter by coagulation and flocs separation. Water Sci. Technol. 27 (11), 1-20. 
Selvapathy, P., Reddy, M.J., 1992. Effect of polyelectrolytes on turbidity removal. Water Supply 10, 175-178.

Tambo, N., Watanabe, Y., 1979. Physical characteristics of flocs-I. The floc density function and aluminum floc. Water Res. 13, 409-419.
Yu, X., Somasundaran, P., 1993. Enhanced flocculation with double flocculants. Colloids Surf. A 81, 17-23.

Zhu, H., Smith, D.W., Zhou, H., Stanley, S.J., 1996. Improving removal of turbidity causing materials by using polymers as filter aid. Water Res. 30, 103-114. 